\title{
The large-scale spatio-temporal variability of precipitation over Sweden observed from the weather radar network
}

\author{
A. Devasthale and L. Norin
}

Atmospheric Remote Sensing Unit, Research and Development Department, Swedish Meteorological and Hydrological Institute (SMHI), Norrköping, Sweden

Correspondence to: A. Devasthale (abhay.devasthale@ smhi.se)

Received: 24 November 2013 - Published in Atmos. Meas. Tech. Discuss.: 11 December 2013

Revised: 30 April 2014 - Accepted: 30 April 2014 - Published: 6 June 2014

\begin{abstract}
Using measurements from the national network of 12 weather radar stations for the 11-year period 2000-2010, we investigate the large-scale spatio-temporal variability of precipitation over Sweden. These statistics provide useful information to evaluate regional climate models as well as for hydrology and energy applications. A strict quality control is applied to filter out noise and artifacts from the radar data. We focus on investigating four distinct aspects: the diurnal cycle of precipitation and its seasonality, the dominant timescale (diurnal versus seasonal) of variability, precipitation response to different wind directions, and the correlation of precipitation events with the North Atlantic Oscillation (NAO) and the Arctic Oscillation (AO). When classified based on their intensity, moderate- to high-intensity events (precipitation $>0.34 \mathrm{~mm} / 3 \mathrm{~h}$ ) peak distinctly during late afternoon over the majority of radar stations in summer and during late night or early morning in winter. Precipitation variability is highest over the southwestern parts of Sweden. It is shown that the high-intensity events (precipitation $>1.7 \mathrm{~mm} / 3 \mathrm{~h}$ ) are positively correlated with NAO and AO (esp. over northern Sweden), while the low intensity events are negatively correlated (esp. over southeastern parts). It is further observed that southeasterly winds often lead to intense precipitation events over central and northern Sweden, while southwesterly winds contribute most to the total accumulated precipitation for all radar stations. Apart from its operational applications, the present study demonstrates the potential of the weather radar data set for studying climatic features of precipitation over Sweden.
\end{abstract}

\section{Introduction}

Precipitation is one of the important components in the global and regional water- and energy cycles and one that has profound influence on human lives from daily to seasonal timescales. From a climate perspective, the changes in precipitation characteristics such as distribution, frequency, and amount and variability can have significant consequences for the long-term planning and consumption of the resources. Therefore, considering the importance of precipitation properties, global and regional climate models often strive to capture their statistical nature as accurately as possible so as to better predict any future changes (Dai, 2006).

From an observational perspective, tools such as rain gauges (Schneider et al., 2011), weather radars (Huuskonen et al., 2013; Zhang et al., 2011) and satellite sensors (Adler et al., 2003) can be employed to monitor and document precipitation behaviour. In recent years, considerable efforts have been dedicated to produce climate-quality observational data records of precipitation based solely on one of these tools or a combination of them. For a high-latitude country like Sweden, weather radars offer a viable alternative to satellite observations and rain-gauge measurements. Satellite-based observations still suffer from limited accuracy over land (esp. at higher latitudes) and rain-gauge stations are spatially sparse. The high spatial and temporal resolutions of weather radars with their wide area coverage at near-real time make them immensely useful for operational monitoring. The success stories of such applications can be seen from international initiatives such as BALTRAD (http://www.baltrad.eu/). 
The usefulness of long-term radar data for the climate applications has also been demonstrated in a number of studies. For example, Rudolph et al. (2011) used a 9-year radar data set to investigate the relationship between precipitation and synoptic-scale weather patterns in the European Alps region, while Rudoplh and Friedrich (2013) have studied the vertical structure of precipitation and its seasonality. Previously Carbone and Tuttle (2008) used radar data over the mainland USA to examine the diurnal characteristics of rainfall and the meteorological conditions driving the diurnal cycle (esp. the role of propagating systems). Overeem et al. (2009) derived a 10-year climatology of radar-based rainfall for climatological and hydrological applications. Matyas (2010) has further emphasized the importance of weather radar for such applications. Germann et al. (2006) have provided solutions using radars to study orographic precipitation in a rather difficult mountainous region of the Swiss Alps.

In Sweden, apart from their operational use, more than a decade of continuous precipitation observations from weather radars located at 12 carefully chosen locations has allowed the investigation of large-scale statistics of precipitation to gain insight into climatic aspects. In the present study this potential of the weather radar network is exploited to explore different aspects of precipitation variability. The focus is especially placed on presenting statistics that can be used for evaluating climate models. The next section describes the weather radar data set, its processing and quality control. Section 3 discusses the results and the final section presents the conclusions.

\section{The weather radar data set}

As part of the Baltic Sea Experiment (BALTEX) the BALTEX Radar Data Centre (BRDC) was established at the Swedish Meteorological and Hydrological Institute in 1999. Since then, the BRDC collects and archives data from around 30 weather radars from countries adjacent to the Baltic Sea. The BRDC also generates radar-based products including radar reflectivity images of individual radars, composite images of radar reflectivity, and images for 3 and $12 \mathrm{~h}$ accumulated precipitation (for details, see Michelson et al., 2000). In this study we have used the BRDC $3 \mathrm{~h}$ accumulated precipitation images to investigate the diurnal and seasonal dependence of precipitation. As our main interest is precipitation over Sweden we have limited the images to areas covered only by the Swedish radars. However, as explained below, measurements very close to and very far from weather radars may have lower quality. We have therefore further limited the data to areas with radius $5 \mathrm{~km}<r<80 \mathrm{~km}$ around the Swedish radars to improve the data quality.

The Swedish weather radar network consists of 12 horizontally polarized Ericsson C-band Doppler radars, providing almost complete national coverage (see Fig. 1 and Table 1). The radars measure reflectivity, radial velocity and

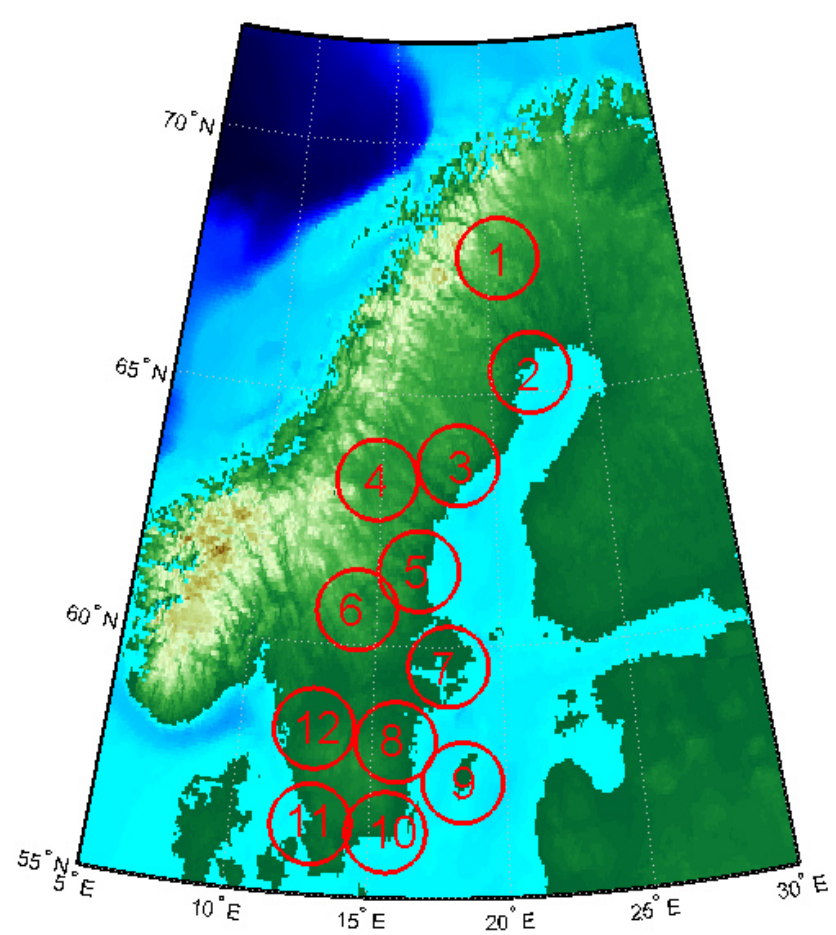

Figure 1. Geographical position of the 12 radars in Sweden. The areas enclosed by circles are used for analysis.

spectrum width. The equivalent radar reflectivity factor, $Z_{\mathrm{e}}$, is measured by the radars in units of dBZ. The Swedish weather radars have a dynamic range of 8 bits and measure $Z_{\mathrm{e}}$ between -30 and $71.6 \mathrm{dBZ}$ in steps of $0.4 \mathrm{dBZ}$. To protect the radar receiver from overload the signal is damped by $60 \mathrm{~dB}$ near the radar, making the data of the first two range bins unusable. The radars have a half-power beam width of $0.9^{\circ}$ and two pulse repetition frequencies are used to increase the maximum unambiguous velocity for the wind field measurements. The data processing managed by the radar signal processor and the data are output in matrices consisting of $120 \times 420$ radar cells for every elevation scan. The radial resolution of each radar cell is $2 \mathrm{~km}$ for the lowest four elevation angles and $1 \mathrm{~km}$ for the others. The azimuthal resolution of a cell is $360 / 420 \approx 0.86^{\circ}$ for all elevation angles. The radars perform azimuthal scans of $360^{\circ}$ around a vertical axis for 10 elevation angles, from 0.5 to $40^{\circ}$. Together, these scans make up polar volume data sets which are provided with an update time of $15 \mathrm{~min}$. Further technical characteristics of the radars are summarized in Table 2.

From the polar volume data sets horizontal cross sections of radar reflectivity at a certain altitude can be generated. Such cross sections are referred to as constant altitude plan position indicator (CAPPI). A similar product is the pseudoconstant altitude plan position indicator (PCAPPI) which is defined as the CAPPI where available, and over areas where no data exist at the specified altitude the measurement nearest in height is selected. At the BRDC the PCAPPI is defined 
Table 1. Listing of weather radar stations over Sweden.

\begin{tabular}{llrrrr}
\hline $\begin{array}{l}\text { Station } \\
\text { number }\end{array}$ & $\begin{array}{l}\text { Station } \\
\text { name }\end{array}$ & WMO ID & Latitude $\left(^{\circ}\right)$ & Longitude $\left(^{\circ}\right)$ & $\begin{array}{r}\text { Altitude } \\
\text { above sea } \\
\text { level }(\mathrm{m})\end{array}$ \\
\hline 1 & Kiruna & 2032 & 67.7088 & 20.6178 & 647 \\
2 & Luleå & 2092 & 65.4309 & 21.8650 & 68 \\
3 & Örnsköldsvik & 2262 & 63.6395 & 18.4019 & 522 \\
4 & Östersund & 2200 & 63.2951 & 14.7591 & 466 \\
5 & Hudiksvall & 2334 & 61.5771 & 16.7144 & 389 \\
6 & Leksand & 2430 & 60.7230 & 14.8776 & 457 \\
7 & Arlanda & 2451 & 59.6544 & 17.9463 & 74 \\
8 & Vilebo & 2570 & 58.1059 & 15.9363 & 223 \\
9 & Ase & 2588 & 57.3035 & 18.4001 & 85 \\
10 & Karlskrona & 2666 & 56.2955 & 15.6103 & 123 \\
11 & Ängelholm & 2606 & 56.3675 & 12.8517 & 209 \\
12 & Vara & 2600 & 58.2556 & 12.8260 & 164 \\
\hline
\end{tabular}

at $500 \mathrm{~m}$ altitude above the corresponding radar and is generated using scans from all available elevation angles.

The BRDC $3 \mathrm{~h}$ accumulated precipitation composite image is generated by converting the equivalent radar reflectivity factor to precipitation rate for individual PCAPPI images, summing the images, adjusting the precipitation rate using rain-gauge measurements, and finally compositing the images. The composite image has a spatial resolution of $2 \times 2 \mathrm{~km}$. At the BRDC the equivalent radar reflectivity factor is converted to precipitation rate $R\left(\mathrm{~mm} \mathrm{~h}^{-1}\right)$ using the empirical relationship $Z_{\mathrm{e}}=a R^{b}$ (see e.g. Battan, 1973), with $a=400, b=2$ for the cold season (October to March) and $a=200, b=1.5$ for the warm season (April to September).

Measurements at increasing distances from the radars are made at increasing heights (with increasing risk of overshooting precipitating clouds). Measurements made at large distances from the radar may therefore be of lower quality. Rain gauge measurements, which are considered to produce high-quality point measurements, are therefore used by the BRDC to calibrate the summed radar images and to adjust for this distance dependence.

The gauge adjustment method employed by the BRDC is based on a method presented by Koistinen and Puhakka (1981) with a number of modifications (Michelson et al., 2000). Rain gauge accumulations are accessed at 06:00 and 18:00 UTC every day. The rain-gauge measurements are corrected using a modified version of the Dynamic Correction Model (Førland et al., 1996) before they are used for the gauge adjustment (Michelson, 2004). Radar accumulation measurements, corresponding to the location of the rain gauges, are used to generate gauge-radar observation pairs. A second-degree polynomial is then fitted to $\log _{10}$ (gauge/radar) as a function of distance from the nearest radar. Only rain-gauge measurements above $0.5 \mathrm{~mm}$ and radar accumulations above $0.1 \mathrm{~mm}$ are taken into account. To avoid overfitting, measurements from the last 7 days are
Table 2. Technical characteristics of the Swedish weather radars.

\begin{tabular}{lll}
\hline Elevation angles & $0.5^{\circ}, 1.0^{\circ}$, & $2.5^{\circ}, 4.0^{\circ}, 8.0^{\circ}$, \\
& $1.5^{\circ}, 2.0^{\circ}$ & $14^{\circ}, 24^{\circ}, 40^{\circ}$ \\
\hline Transmitted power & $250 \mathrm{~kW}$ & $250 \mathrm{~kW}$ \\
Wavelength & $5.35 \mathrm{~cm}$ & $5.35 \mathrm{~cm}$ \\
Gain & $44.7 \mathrm{~dB}$ & $44.7 \mathrm{~dB}$ \\
Pulse width & $0.5 \mu \mathrm{s}$ & $0.5 \mu \mathrm{s}$ \\
Beam width & $0.9^{\circ}$ & $0.9^{\circ}$ \\
PRFs & $600 / 450 \mathrm{~Hz}$ & $1200 / 900 \mathrm{~Hz}$ \\
Rotational speed & $2 \mathrm{rpm}$ & $2 \mathrm{rpm}$ \\
Measurement radius & $240 \mathrm{~km}$ & $120 \mathrm{~km}$ \\
Radial resolution & $2 \mathrm{~km}$ & $1 \mathrm{~km}$ \\
Azimuthal resolution & $0.86^{\circ}$ & $0.86^{\circ}$ \\
Range bins & 120 & 120 \\
Azimuth gates & 420 & 420 \\
\hline
\end{tabular}

used to ensure that sufficiently many observation pairs exist. At each following $3 \mathrm{~h}$ interval up to the next $12 \mathrm{~h}$ analysis, a 3-hourly composite accumulation analysis is generated based on the previously determined relationships between $\log _{10}$ (gauge/radar) and range. This results in a rain-gauge adjusted radar composite image in which the quantitative accuracy is largely determined by the rain-gauge values and the spatial distribution is determined by the radar data.

The use of the 7-day time window makes the BRDC's gauge adjustment method very robust, as it ensures that sufficiently many gauge-radar observation pairs exist, but it may also make the method less accurate in periods in which rapid changes to the vertical profile of reflectivity occur. Koistinen and Michelson (2002) evaluated the performance of the BRDC gauge adjustment method on $12 \mathrm{~h}$ accumulation images using data from the winter 1999-2000 and the summer of year 2000. They found that the average bias of the gauge-adjusted accumulation image and the rain-gauge 
measurements was less than $1 \mathrm{~dB}$ at all ranges in summer and less than $1 \mathrm{~dB}$ in winter for ranges up to $160 \mathrm{~km}$.

In order to remove radar echoes not originating from precipitation the BRDC applies a filter using satellite observations. In areas classified as cloud free by the satellite observations this filter removes all radar echoes. For details, see Michelson (2006).

Further improvements to the BRDC's radar accumulation images could be made by introducing precipitation phase type-dependent $Z-R$ relationships (in order to separate rain from e.g. snow or hail) and by treating convective and stratiform precipitation separately. By using a vertical profile of reflectivity (VPR) correction before applying the gauge adjustment technique the "bright band" effect (strong returns from the melting layer) could be minimized. Applying such methods would almost certainly improve the quality of the data. However, one of the great strengths of the BRDC's data set is that its methods have remained unchanged for more than a decade, making the data set homogeneous and well suited for long-term studies.

Obstacles such as high buildings or mountains in line of sight of radar may yield large reflections (clutter) that the built-in clutter filters are sometimes unable to suppress completely. This can occasionally leave unreasonably large precipitation values in the data. For the purpose of this study we have therefore, in addition to the abovedescribed quality controls employed by the BRDC, applied a filter that removes any radar cell that on a given month or year shows an accumulated precipitation higher than $500 \mathrm{~mm} \mathrm{month}^{-1}$ or $2000 \mathrm{~mm}$ year $^{-1}$ (the highest amounts ever recorded by rain gauges in Sweden are $429 \mathrm{~mm} \mathrm{month}^{-1}$ and $1866 \mathrm{~mm}$ year $^{-1}$ ).

In this study we have used all pixels from the composite images found within a radius of $5-80 \mathrm{~km}$ around each of the 12 Swedish radar stations to generate data sets of accumulated precipitation every $3 \mathrm{~h}$. The number of pixels for any radar station is approximately 5150 . However, the abovedescribed filter can reduce the actual number of pixels on a given year and month. Figure A1 in the Appendix shows the number of pixels used for each of the radars as a function of time. The smallest number of pixels for any radar at any time was 3499 but for the majority of the time the numbers of pixels removed were far fewer. The average number of pixels used per month per radar was 5024. The smallest number of pixels (3499) is still more than enough to statistically represent rainfall distribution (the calculated margin of error remains less than $1.6 \%$ ). Furthermore, probability distribution functions (PDFs) of rainfall for all stations look very similar (as reflected in Fig. 3), in spite of different number of samples. We have also inspected the PDFs for radar stations during periods of less data and compared to the corresponding PDFs for periods with near-full coverage. The difference between these PDFs is negligible. These aspects give us confidence that the sampling errors are least likely to influence our results. The availability of radar data in time is shown in
Table 3. Binning of precipitation intensity into eight bins.

\begin{tabular}{ll}
\hline Bin & $\begin{array}{l}\text { Precipitation } \\
\text { intensity }(\mathrm{mm} / 3 \mathrm{~h})\end{array}$ \\
\hline 1 & $0.1-0.14$ \\
2 & $0.14-0.21$ \\
3 & $0.21-0.34$ \\
4 & $0.34-0.55$ \\
5 & $0.55-0.96$ \\
6 & $0.96-1.7$ \\
7 & $1.7-3.25$ \\
8 & $3.25-100$ \\
\hline
\end{tabular}

Fig. A2 in the Appendix. During the majority of the time the availability of radar composites is well over $90 \%$. During a few months from 2000 to 2004 the BRDC experienced data loss (resulting in 11 months with less than $75 \%$ data availability).

Since the main goal of the present study is to learn more about the large-scale features, the spatial information of the pixels around an individual radar station is not used in the analysis.

\section{The spatio-temporal variability of precipitation}

We focus on investigating four distinct aspects of the spatiotemporal variability in precipitation in the present study. First, we examine the diurnal cycle of precipitation and its seasonality. Then, we investigate the dominant timescale (diurnal versus seasonal) of the precipitation variability. Further, the correlation of precipitation with the major modes of natural variability in the Northern Hemisphere, i.e. the North Atlantic Oscillation (NAO) and the Arctic Oscillation (AO), is examined. And finally, we investigate the influence of wind direction on the observed precipitation amount.

\subsection{Diurnal variations in precipitation}

Simulating the diurnal cycle of precipitation accurately is one of the main challenges faced by climate models. For example, coupled climate models have a tendency to produce convective precipitation too early and too frequently compared to observations during the warm season (Dai, 2006; Jeong et al., 2011). In general, the diurnal cycle of precipitation depends on many factors, such as geographical position, season, surface characteristics etc. But perhaps the most governing and dynamical factor influencing the diurnal cycle is the role of atmospheric conditions leading to precipitation. For example, spatio-temporal characteristics of precipitation are quite different during the passage of frontal systems as opposed to those during local convection. This is especially true for Sweden where both the frontal systems and local convection contribute to the total annual precipitation. 
Walther and Bennartz (2006) showed that, over the Baltic Sea region (where Sweden has a very long coastline), precipitation events attributed to frontal systems constitute twothirds of all events. However, they also observed strong seasonal variability in the number of precursor frontal systems. For example, the fraction of non-frontal systems was by a factor of 2-3 higher during the summer half of the year. This aspect certainly influences the diurnal cycle of precipitation. For example, the peak time of diurnal cycle will vary considerably from one synoptic event to another depending on the dynamical state of the atmosphere and surface interactions during the passage of the frontal system over the study region. However, during peak summer, strong surface heating and moisture availability leads to a well-defined diurnal cycle of convection (and the resulting precipitation) that usually peaks during the late afternoon or early evening. Figure 2 shows the precipitation frequency in order to study the intrinsic variability in the peaks of the diurnal cycle for 12 radar stations in Sweden during four seasons. The precipitation frequency is computed as the number of observations when precipitation was encountered divided by total number of observations. Only in the summer season do the majority of stations show diurnal cycles peaking at the same time (15:00-18:00 UTC), while in the winter season, there is no clear diurnal peak time tendency across the stations. The other two seasons show mixed peak times. The majority of stations show well-defined and higher amplitudes in precipitation frequency during summer, while the diurnal cycles are quite flatter in other seasons, especially in spring.

It is also of interest to understand when the precipitation events with different intensities peak during different seasons. This information is not only useful to evaluate climate models, but also for hydrology and for the planning of resources and energy. Therefore, as shown in Fig. 3, we classified $3 \mathrm{~h}$ precipitation accumulations into eight categories based on their intensities. The bin size is chosen in such a way that there are roughly the same numbers of samples in each bin, thus making statistical comparison more robust. Table 3 summarizes the boundaries of each intensity bin. Such classification of precipitation events provides us with more detailed knowledge of the timing of their occurrence at different intensities. Figure 4 shows the results of this analysis. In winter and spring, there is no clear general tendency in the timing of precipitation peak across radar stations and intensity bins. It is to be kept in mind that, as shown in Fig. 2, the diurnal cycles of precipitation during these months are quite flat. The processes leading to precipitation (for example, passage of mid-latitude cyclones) do not depend, to a first order, on the local-scale diurnal variations and thus do not result in any preferred timing of peak in precipitation. In summer, the majority of stations show a late afternoon peak for low- and moderate-intensity events. In autumn the low-intensity events peak during late night or early morning. In the majority of cases, the highest intensity events (bin 8)
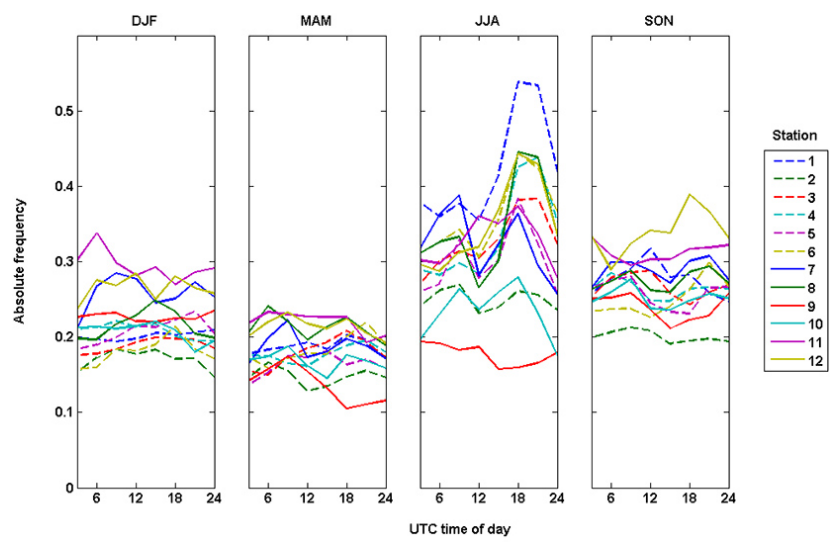

Figure 2. Diurnal cycle of total precipitation for the 12 radar stations and its seasonal variation. The values on the $x$ axis are UTC hours.

occur between late evenings to early morning irrespective of the season.

Our results for the diurnal cycle of precipitation are in general agreement with the comprehensive study by Jeong et al. (2011), who use data from the network of rain-gauge stations across Sweden. Our value addition lies in the fact that we further classify precipitation based on intensity to investigate diurnal cycles and also that we analyse the four seasons separately. Furthermore, our analysis is based on a completely different observational platform with a much higher spatial resolution.

\subsection{Diurnal versus seasonal variability}

Since precipitation is a result of various thermodynamical and radiative processes and their couplings and interactions with each other, a great deal of confidence can be placed in a climate model if it is able to simulate precipitation variability at various spatio-temporal scales. The coefficient of variation (COV, defined as standard deviation divided by mean) is a simple yet very powerful statistical metric to study precipitation variability. It facilitates comparison for the quantities that could have different sample means, as in the case of the present study, where there is large precipitation variability across radar stations (see Fig. 2). In Fig. 5, COV is expressed as a function of each $3 \mathrm{~h}$ time bin and season for each of the 12 radar stations. This not only provides us with an overview of precipitation variability across all stations, but more importantly, allows us to compare whether the diurnal or seasonal variability is more important for an individual station. We computed the areal average precipitation amount for each $3 \mathrm{~h}$ time step in a chosen season. Then we computed the standard deviation over all these areal averages and divided it by the mean of all these areal averages.

The highest precipitation variability is observed over southwestern Sweden, central eastern Sweden and the northernmost parts of the country. On the other hand, lower 


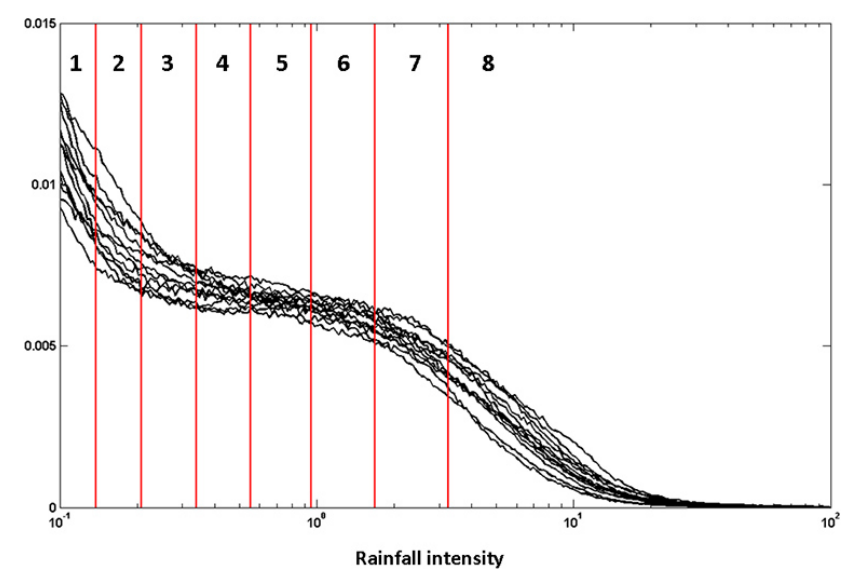

Figure 3. Normalized frequency of occurrence of accumulated precipitation intensity $(\mathrm{mm} / 3 \mathrm{~h})$ for the 12 radar stations based on the entire data record (2000-2010). The vertical lines show eight bins chosen in such a way that the number of observations is roughly similar in each intensity bin.

precipitation variability is observed over the southeastern parts. The northeastern parts of the country also experience lower variability. There is also a general tendency that the seasonal variations in precipitation are stronger during late nights and early mornings (time bins 1 and 8 ).

\subsection{Correlation with NAO and AO indices}

The North Atlantic Oscillation (NAO) and the Arctic Oscillation (AO) are considered to be dominant modes of atmospheric variability in the Northern Hemisphere (Hurrell, 1995; Thompson and Wallace, 1998; Christiansen, 2002). The NAO and AO indices are defined by taking into consideration different physical metrics. While the emphasis is placed on the strength of atmospheric circulation over the Arctic and the resulting geopotential height anomalies in defining the AO index, the state of the two pressure systems in the North Atlantic Ocean (one over the Icelandic region and the other over Azores) is taken into account while defining the NAO index. There exists debate as to which one of these oscillatory systems can be understood in a physically meaningful way (Ambaum et al., 2001). However, there is no ambiguity with regard to their influence on the climates of the North Atlantic Ocean and surrounding continents. They have first-order impact on the observed inter-annual changes in the water and energy cycle over these regions. This also applies to the Scandinavian region, especially during the winter half of a year. The AO and NAO indices used in this study are obtained from the National Oceanic and Atmospheric Administration's (NOAA) Climate Prediction Centre (CPC), and are found here: http://www.cpc.ncep.noaa.gov/products/ precip/CWlink/daily_ao_index/teleconnections.shtml) They are computed as follows. The Empirical Orthogonal Functions (EOF) analysis is carried out on the standardized
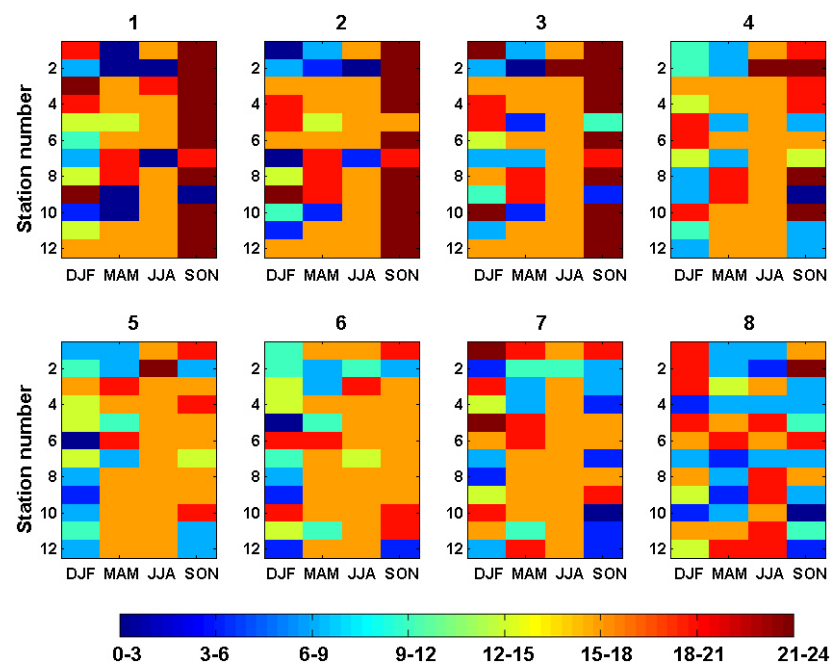

3-6

$6-9$

$9-12$

12-15

15-18

$18-21$

21-24

Figure 4. UTC time (hour of a day) of the diurnal cycle peak. Eight subplots correspond to eight precipitation intensity bins defined in Table 3, and each subplot shows peak times for the 12 stations and four seasons.

$1000 \mathrm{hPa}$ geopotential height anomalies poleward of $20^{\circ} \mathrm{N}$. The first mode from this analysis, which is the leading mode of variability, is used to construct $\mathrm{AO}$ indices by projecting $1000 \mathrm{hPa}$ height anomalies onto this mode. In the case of the NAO index, Rotated Principle Component Analysis (RPCAm using Varimax rotation) is carried out on $500 \mathrm{hPa}$ geopotential height anomalies to obtain the leading teleconnection pattern. The NAO index is further calculated using least-squares regression.

The changes in the meridional temperature gradient and strengthening/weakening of westerlies during different phases of these oscillations eventually determine the advection of heat and moisture across the North Atlantic and the neighbouring continents. In general it is observed that during their positive phases, the winter storms are more frequent and extend over northern Europe, especially Scandinavia. Chen (2000), Linderson (2001) and Hellström (2005) have analysed different weather states and circulation patterns over Sweden. Chen (2000) and Linderson (2001) have shown that, during winter (when NAO/AO are most active), westerly and southwesterly winds are often dominating the weather state classification.

Figure 6 provides an overview of meteorological conditions during strongly positive $(>1 \sigma)$ and negative phases $(<-1 \sigma)$ of the Arctic Oscillation over northern Europe. It shows the dominant wind patterns and temperature and water vapour anomalies at $850 \mathrm{hPa}$ for 2002-2012. The wind data are obtained from the European Centre for Medium Range Weather Forecasts (ECMWF) Interim reanalysis (ERA-Interim) (Dee et al., 2011), while temperature and water vapour retrievals from the Atmospheric Infrared Sounder (AIRS) sensor onboard NASA's Aqua satellite 

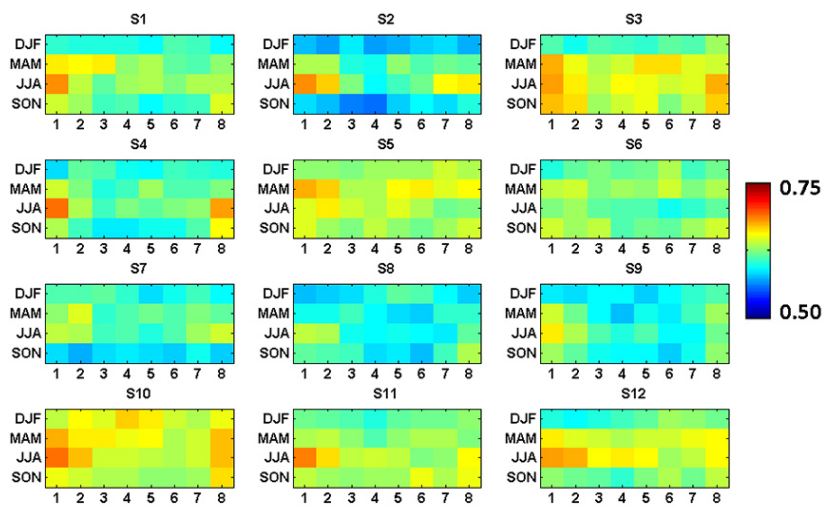

3-hourly bins

Figure 5. Coefficient of variation (standard deviation divided by mean) for precipitation for each $3 \mathrm{~h}$ bin and season. The 12 subplots correspond to the 12 radar stations (denoted by $\mathrm{S} 1$ to S12) over Sweden. The geographical location of these stations is shown in Fig. 1. The $3 \mathrm{~h}$ bins numbered $1-8$ are UTC hours from 00:00-03:00, 03:00-06:00, 06:00-09:00, 09:00-12:00, 12:00-15:00, 15:00-18:00, 18:00-21:00 and 21:00-24:00 respectively.

are used for analysis (Chahine et al., 2006; Fetzer, 2006). It can be clearly seen that, during positive phases, strong westerly/southwesterly winds bring heat and moisture towards the Scandinavian region as is evident in the positive temperature and water vapour anomalies, while the opposite is true during negative phases. As the contribution of convective precipitation to the total is very small over Sweden during winter due to the lack of solar heating, the frontal systems remain the dominant driver behind the observed anomalies in temperature and water vapour and thus the source of precipitation (e.g. Walther and Bennartz, 2006). Since these systems are in turn heavily influenced by NAO and AO indices, the precipitation response to both indices is also expected. This aspect is investigated in the present study and the results are shown in Fig. 7. We divided precipitation events into three categories based on their intensity, namely low (intensity $<=0.34 \mathrm{~mm} / 3 \mathrm{~h}$ ), medium $(0.34<$ intensity $<=1.7 \mathrm{~mm} / 3 \mathrm{~h})$ and high $>1.7 \mathrm{~mm} / 3 \mathrm{~h})$, with the further aim of understanding whether different intensity events respond differently to the changes in largescale circulation represented by the NAO and AO indices. Figure 7 shows the correlation of accumulated monthly precipitation with these indices (left column) for two scenarios, first when only the DJF months are included in the analysis (top two rows) and the other when the NDJFM months are included (bottom two rows). The subplots to the right show confidence levels at which these correlations are significant. It is indeed interesting to note that for the majority of the radar stations, high-intensity precipitation events are positively correlated with the monthly NAO and $\mathrm{AO}$ indices. The low-intensity events, on the other hand, are a)

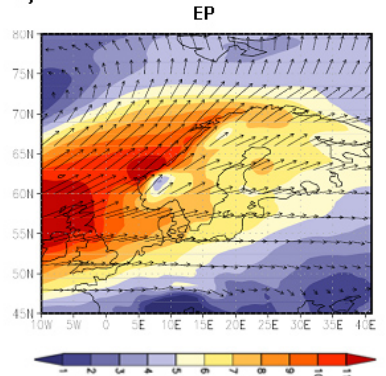

c)

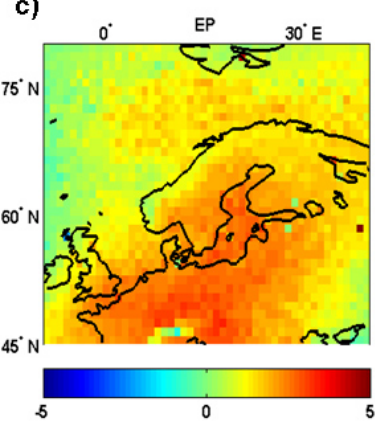

e)

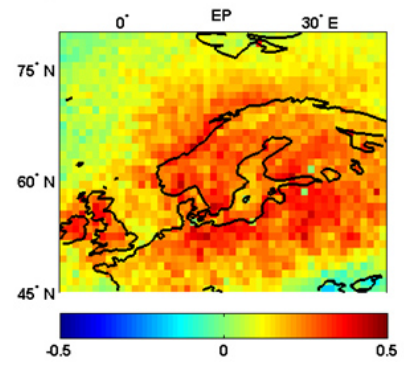

b)

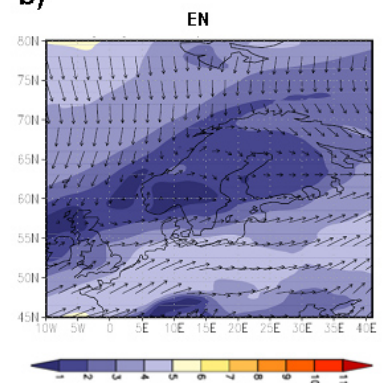

d)

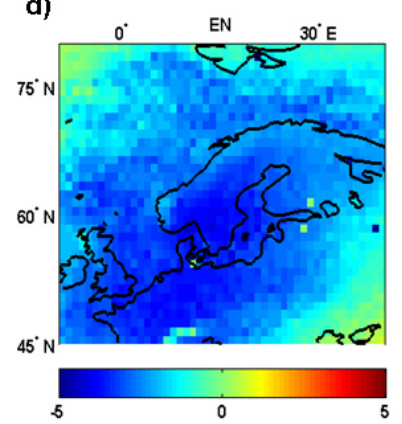

f)

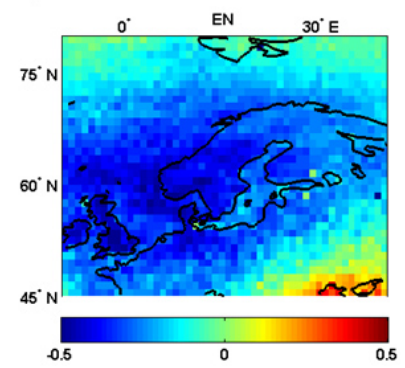

Figure 6. An overview of meteorological conditions at $850 \mathrm{hPa}$ during enhanced positive (EP) and negative (EN) phases of the Arctic Oscillation. The top row (a and $\mathbf{b})$ shows wind conditions $\left(\mathrm{m} \mathrm{s}^{-1}\right)$, the middle row shows temperature anomalies ( $\mathbf{c}$ and $\mathbf{d}$; in $\mathrm{K}$ ) and the bottom row shows water vapour mass mixing ratio anomalies (e and $\mathbf{f}$; in $\mathrm{g} \mathrm{kg}^{-1}$ ). The data from November through March from 2003-2012 are used.

negatively correlated. The statistical significance of these correlations is also very high. In particular, high-intensity events over northern Sweden are strongly positively correlated with AO/NAO indices, while low-intensity events over southeastern Sweden are strongly negatively correlated. When November and March months are included in the analysis, the general tendency of positive/negative correlation with high/low-intensity events becomes even stronger. Station 1 is most northerly in the study area. The AO-type variability has the first-order impact on the precipitation characteristics over this region during the winter half of the year. The Atlantic storms reaching far easterly regions over the Norwegian Sea during positive phases of the $\mathrm{AO}$ and subsequent baroclinic instabilities affect not only high-intensity precipitation events, but also meteorological 


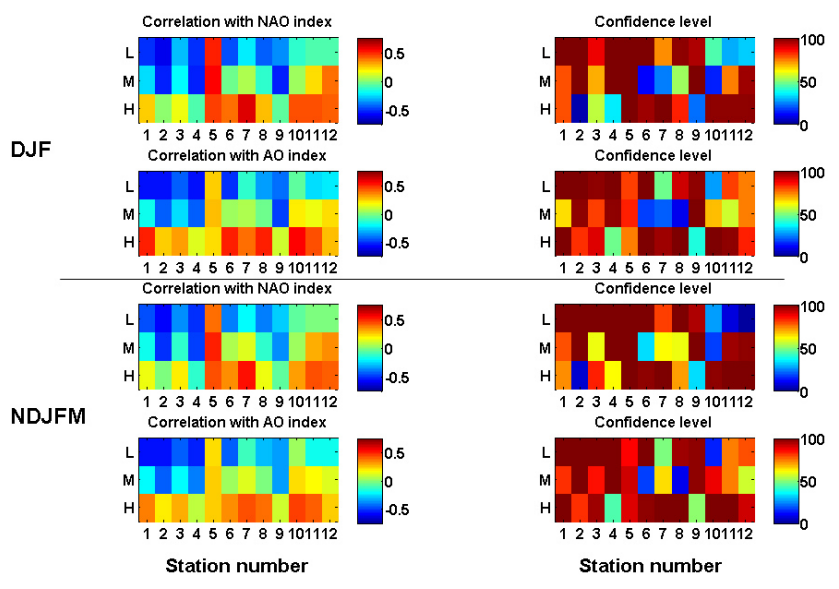

Figure 7. Correlation of low (L, intensity $<0.34 \mathrm{~mm} / 3 \mathrm{~h}$ ), medium (M, $0.34<$ intensity $<1.7 \mathrm{~mm} / 3 \mathrm{~h}$ ) and high $(\mathrm{H}$, intensity $>1.7 \mathrm{~mm} / 3 \mathrm{~h}$ ) intensity precipitation events (left column) with the NAO and AO indices over the 12 radar stations. The top two rows show results for the DJF months, and the bottom two rows show results for the NDJFM months. At right, columns shows confidence levels (0-100\%) at which the observed correlations are significant.

regimes that lead to persistent drizzling. In addition, during the last decade, the centre of action of AO has shifted more towards easterly regions such that it has greater impact on this northerly station.

The results point out the influence of $\mathrm{AO} / \mathrm{NAO}$ on the precipitation patterns over Sweden. Considering the fact that nearly $50 \%$ of energy production in Sweden is based on hydropower, where precipitation plays an important role, any future change in the influence of $\mathrm{AO} / \mathrm{NAO}$ on precipitation will likely have an impact on the national energy policy (Cherry et al., 2005). Further regional modelling studies are required to investigate these aspects in detail.

A few previous studies have investigated the influence of large-scale circulation on Swedish precipitation (e.g. Busuioc et al., 2001; Johansson and Chen, 2003; Uvo, 2003; Hellström, 2005; Gustafsson et al., 2010). In particular, Busuioc et al. (2001) and Uvo (2003) analysed the relationship of NAO with precipitation over Sweden. It is difficult to directly compare our results with those studies due to the different study periods, lengths of data records and regimes of NAO. Nevertheless, it is interesting to note some similarities - for example, relatively high correlations over northern Sweden and low correlations over southeastern Sweden. By partitioning the precipitation events into low, medium and high categories and by analysing the precipitation record for the most recent decade, here, we complement these earlier studies.

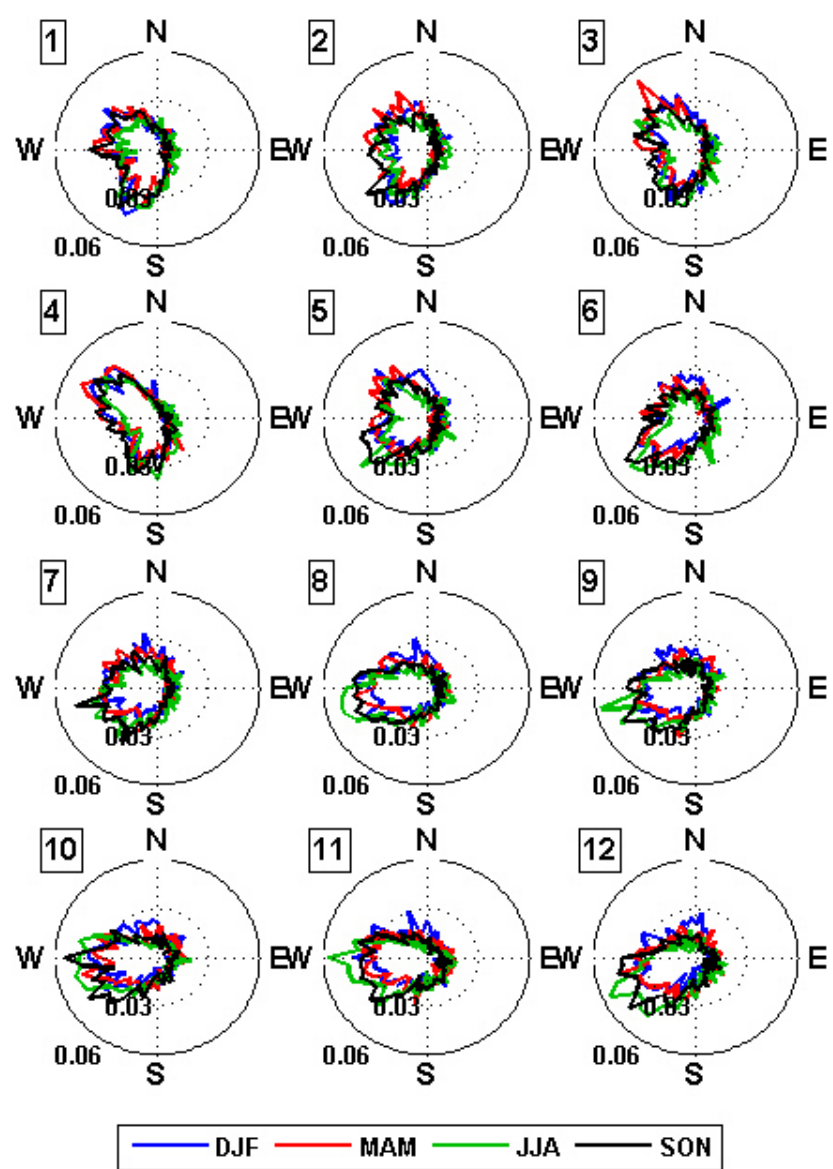

Figure 8. Distribution of wind direction at $850 \mathrm{hPa}$ at the 12 radar stations during different seasons based on the daily data from ERAInterim reanalysis. The PDFs were computed for the same time period as that of radar data (i.e. 2000-2010).

\subsection{Precipitation response to wind direction}

Having detailed knowledge of precipitation response to wind direction is important for a country like Sweden where a varied directional interplay of meteorology, topography and neighbouring oceanic regimes eventually determines the longevity of frontal systems and the amount of moisture transport in the atmosphere. For example, the conditions are often conducive for precipitation when strong and moist winds from a westerly direction (North Atlantic/North Sea origins) arrive over land, compared to conditions under dryer and colder winds of northeasterly origin. Figures 8 and 9 show the PDF of wind direction and the corresponding mean wind strength at $850 \mathrm{hPa}$ over the locations of the 12 radar stations. The PDFs were computed for the same time period as that of radar data (i.e. 2000-2010) using daily averaged ERA-Interim data (Dee et al., 2011). The grid boxes covering the radar domain were averaged. It is evident that, in general, westerly winds dominate over all locations irrespective of season. In northern Sweden, both northwesterly 


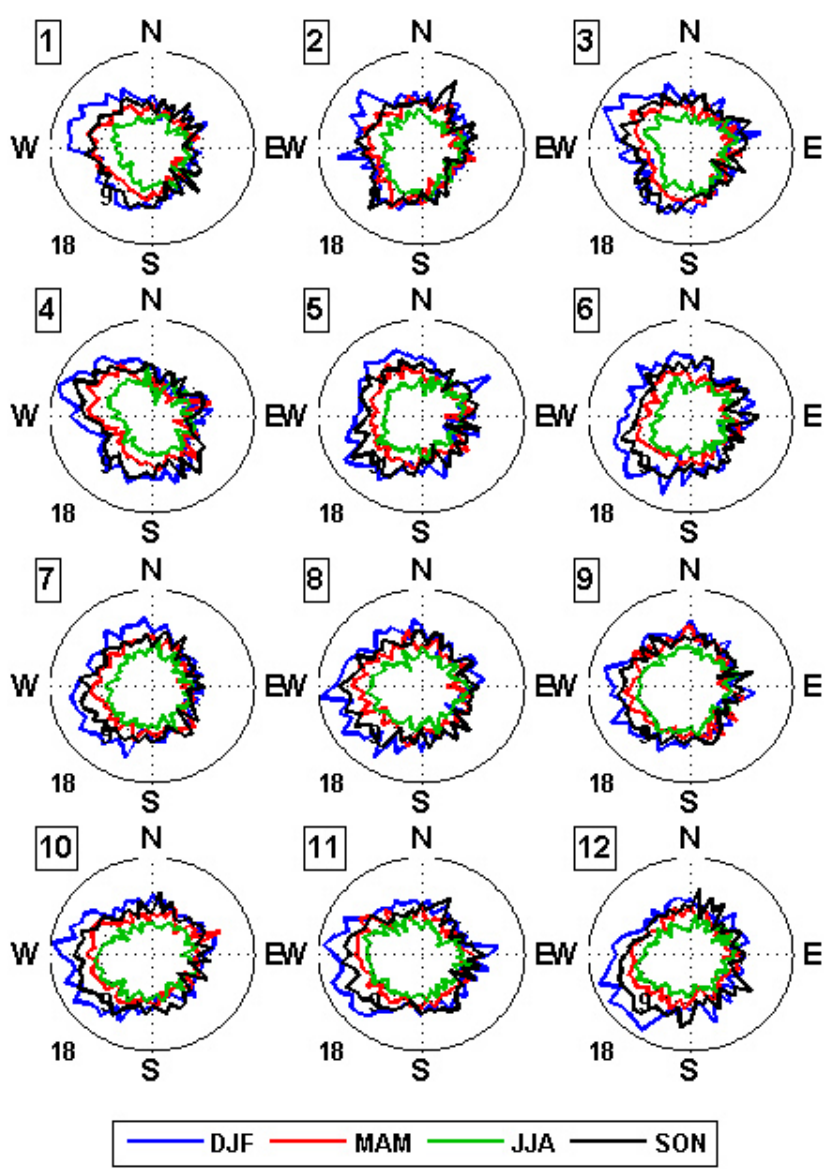

Figure 9. Average wind speed at $850 \mathrm{hPa}$ corresponding to the wind directions shown in Fig. 8 at 12 radar stations during different seasons based on the daily data from ERA-Interim reanalysis.

and southwesterly winds dominate, and in southern Sweden, westerly and southwesterly winds are most frequent. In comparison to wind direction, the distribution of wind strength is much more uniform across all stations. During autumn and winter, winds are generally stronger.

In order to investigate the precipitation response to these prominent wind directions, we pose ourselves two questions:

a. For a given radar location, which wind direction is likely to produce a high average daily precipitation rate?

b. For a given radar location, which wind direction leads to most frequent precipitation occurrence?

To answer these questions, for a given radar station, we first computed average daily precipitation rate under different wind conditions. In the case of each wind condition, we then divide average daily precipitation rate by the sum of average daily precipitation rates under all wind conditions. This gives us the relative importance of a particular wind condition (Fig. 10). Since a particular wind condition that produces high precipitation rate may not necessarily lead to most frequent precipitation occurrence, we investigated the latter in
Fig. 11. For a given radar station, we computed the relative contribution of each wind condition to the total number of precipitation events.

Figure 10 shows a clear tendency that in northern Sweden (station 1 up to station 7) southeasterly winds are mainly responsible for the highest daily precipitation rate (nearly $40 \%$ of the time), while in the southern parts of Sweden it is southwesterly winds that lead to the highest daily precipitation rate events. The latter is especially true for stations near the southwestern coast. In the case of the northerly stations, Norwegian mountain ranges along Sweden's western border hinder frontal systems from producing high daily precipitation (in seasonal average). But when southeasterly winds coming from continental Europe pick up moisture over the Baltic Sea, they have higher potential for producing high daily precipitation rate events. In summer, even the southern stations are influenced by south- or northeasterly winds. Station 9 , located on the island of Gotland in the Baltic Sea, shows an interesting seasonality. In summer, southeasterly winds are responsible for producing nearly half of all the highest daily precipitation rate events, while in autumn, the contribution from northeasterly winds is slightly higher. In winter, the contribution from southerly and easterly winds is nearly equal.

Although winds originating from a southeasterly direction often lead to intense precipitation events, Fig. 11 interestingly shows that southwesterly winds contribute most to the total accumulated precipitation. This in general holds true for all stations during all seasons, although this tendency is more clearly observed over southern Sweden compared to northernmost parts of the country.

\section{Conclusions and outlook}

With their accurate measurements of precipitation and high spatio-temporal resolution, weather radars have been routinely used for operational meteorological applications for many years. The Swedish radar network, connecting 12 such radars, has been operational for more than a decade and covers nearly the entire country. Aside from its operational use, the valuable decade long data record from these radars remains underutilized for other applications.

In this study we exploited 11 years (2000-2010) of data record to study climatic features of precipitation over Sweden. Four aspects relevant for climate applications and evaluation of regional climate models have been investigated, namely diurnal cycle, seasonal versus diurnal variability, influence of NAO and $\mathrm{AO}$ on precipitation, and finally precipitation response to wind direction. It is observed that the majority of the radar stations show diurnal cycles peaking during later afternoon in summer, while there is no such general tendency during other seasons. When the precipitation events are categorized based on intensity, there is a general tendency that the moderate- and high-intensity events occur 
DJF
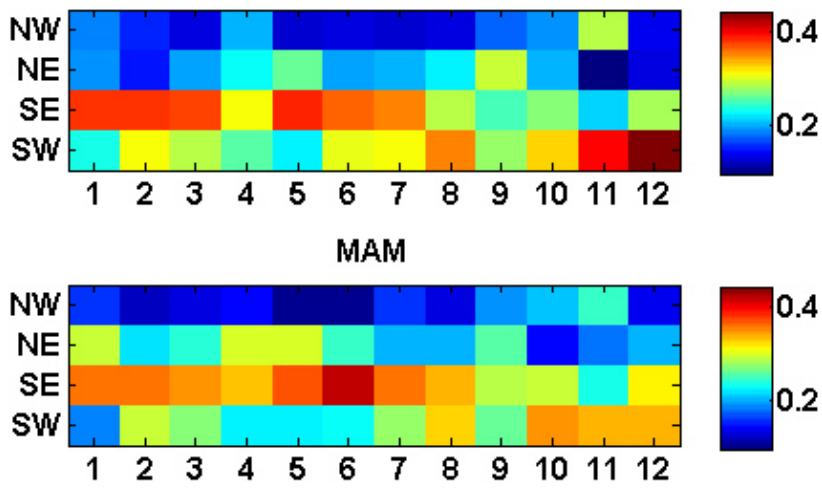

JJA
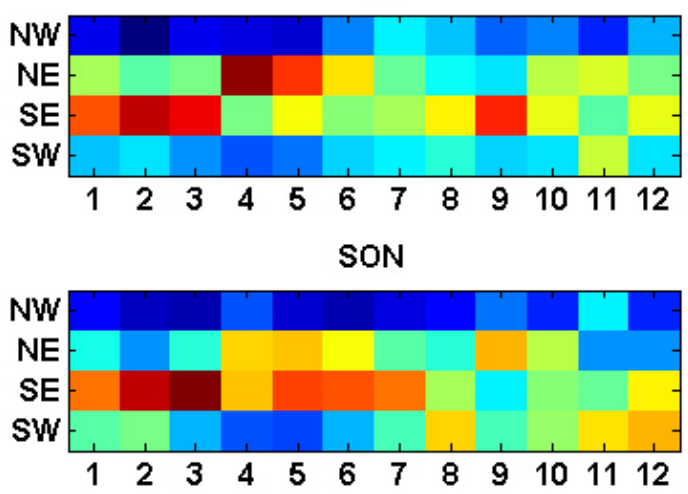

Figure 10. Relative contribution of wind direction to the average daily precipitation rate at each of 12 radar stations during four seasons. Wind directions are abbreviated as NW (northwesterly), NE (northeasterly), SE (southeasterly) and SW (southwesterly).

also during late afternoon in summer, while they peak during late night or early morning in winter. The high-intensity events (precipitation $>1.7 \mathrm{~mm} / 3 \mathrm{~h}$ ) over the majority of the radar stations are positively correlated with the NAO and $\mathrm{AO}$ indices (especially in northern Sweden), while the lowintensity events are negatively correlated. The southeasterly stations show statistically significant high negative correlations. This demonstrates the influence of large-scale advection on the total precipitation during different phases of the $\mathrm{NAO}$ and AO. It is further shown that southeasterly winds often lead to events with highest daily precipitation rate over central and northern Sweden, while southwesterly winds contribute most to the total accumulated precipitation for all radar stations.
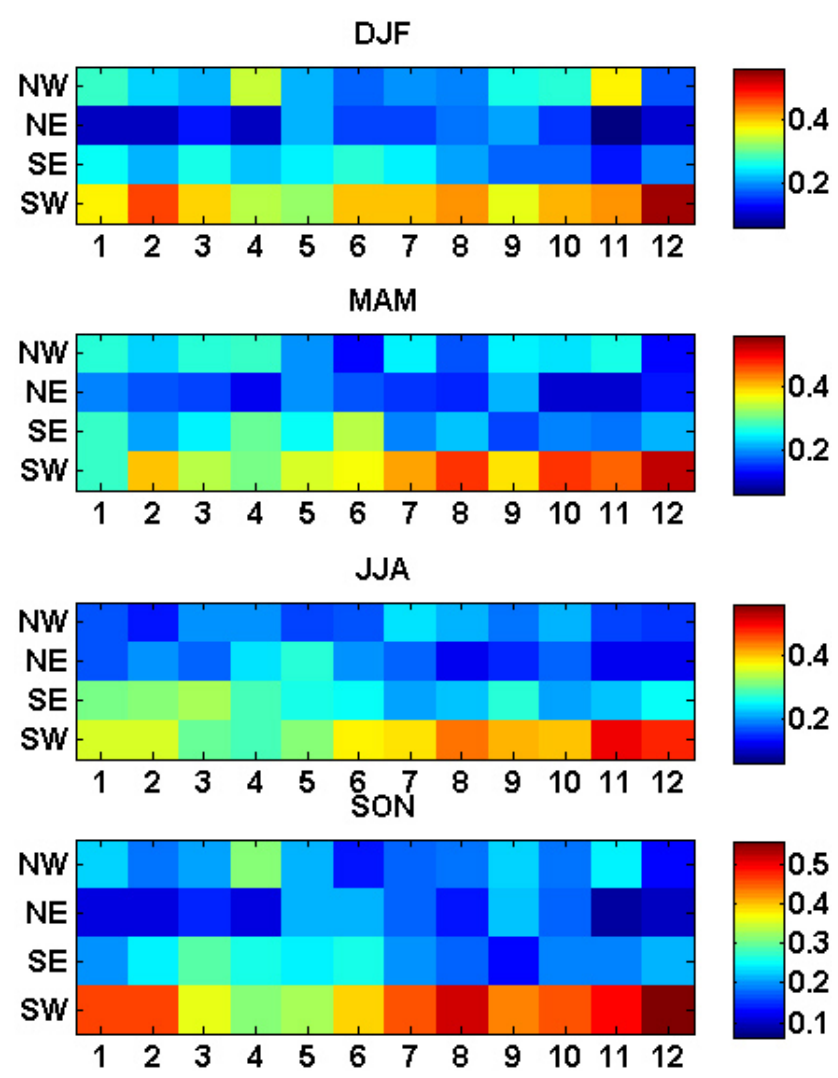

Figure 11. Relative contribution of wind direction to the total number of precipitation occurrences.

The present study demonstrates the potential of the weather radar network data set for climate applications over Sweden. In particular, these results are useful to evaluate the fidelity of regional climate models. Since radar-based monitoring will continue for a long time in the future and since we can capitalize on the lessons learned from the experience of generating satellite-based long-term cloud climatologies, this long-term data set could further provide deeper insights into other climatological features and trends in precipitation over Sweden in the future. In view of this, we plan to carry out a feasibility study to harmonize the cross-calibration of radars in future, quantify uncertainties in precipitation estimates and facilitate the generation of a climate-quality data record from this radar network. We further plan to take a three-tier approach whereby we aim to intercompare and harmonize rain gauge, radar and satellite estimates of precipitation so as to exploit the strengths of each observing system over Sweden. 
Appendix A: Radar data samples and availability

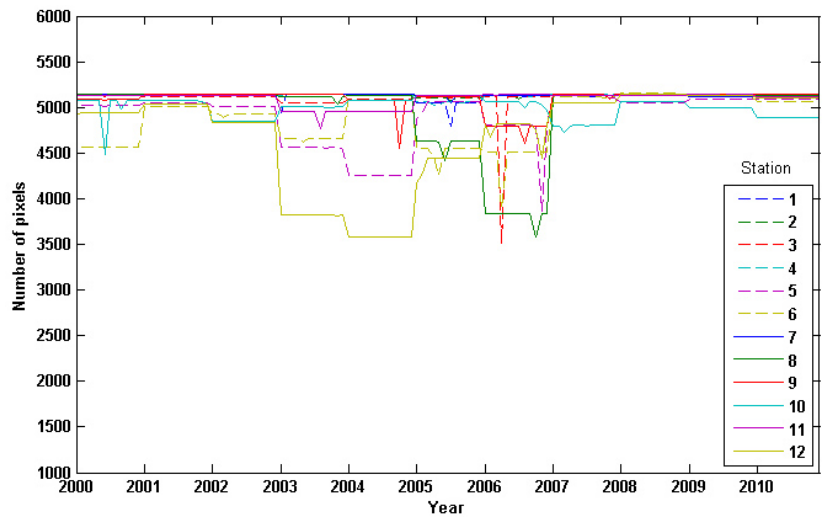

Figure A1. The number of average monthly pixels from each of the 12 radars used in the analysis.

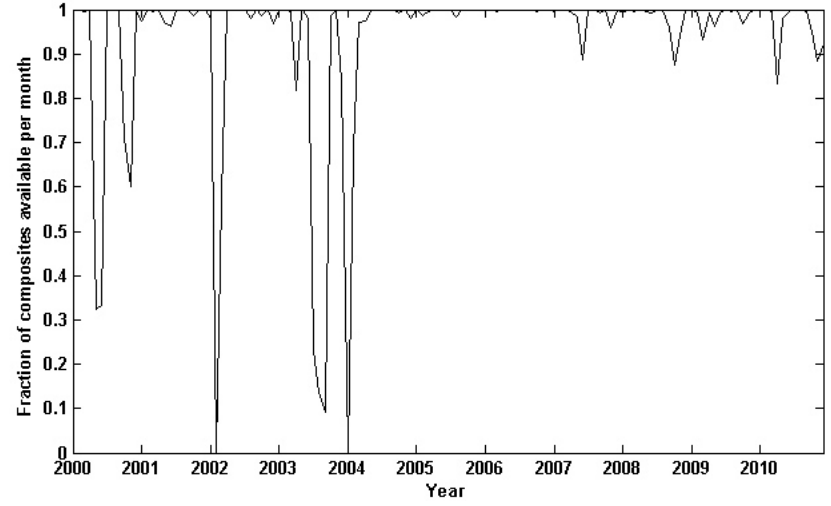

Figure A2. Availability of radar data as a function of time. 
Acknowledgements. The authors would like to thank those many who were/are involved in the establishment and running of the weather radar network over Sweden. ERA-Interim data were obtained from the ECMWF data centre and AIRS-Aqua data obtained from the NASA ASDC. Abhay Devasthale acknowledges the support of the Swedish National Space Board.

Edited by: A. Stoffelen

\section{References}

Adler, R. F., Huffman, G. J., Chang, A., Ferraro, R., Xie, P., Janowiak, J., Rudolf, B., Schneider, U., Curtis, S., Bolvin, D., Gruber, A., Susskind, J., and Arkin, P.: The Version 2 Global Precipitation Climatology Project (GPCP) Monthly Precipitation Analysis (1979-Present), J. Hydrometeorol., 4, 1147-1167, 2003.

Ambaum, M. H. P., Hoskins, B. J., and Stephenson, D. B.: Arctic Oscillation or North Atlantic Oscillation?, J. Climate, 14, 34953507, 2001.

Battan, L. J.: Radar observation of the atmosphere, University of Chicago Press, 324 pp., 1973.

Busuioc, A., Chen, D., and Hellström, C.: Temporal and spatial variability of precipitation in Sweden and its link with the large scale atmospheric circulation, Tellus A, 53, 3, 348-367, 2001.

Carbone, R. E. and Tuttle, J. D.: Rainfall occurrence in the US warm season: the diurnal cycle, J. Climate, 21, 4132-4136, 2008.

Chahine, M. T., Pagano, T. S., Aumann, H. H., Atlas, R., Barnet, C., Blaisdell, J., Chen, L., Divakarla, M., Fetzer, E. J., Goldberg, M., Gautier, C., Granger, S., Hannon, S., Irion, F. W., Kakar, R., Kalnay, E., Lambrigtsen, B. H., Lee, S.-Y., Le Marshall, J., McMillan, W. W., McMillin, L., Olsen, E. T., Revercomb, H., Rosenkranz, P., Smith, W. L., Staelin, D., Strow, L. L., Susskind, J., Tobin, D., Wolf, W., and Zhou, L.: AIRS: Improving Weather Forecasting and Providing New Data on Greenhouse Gases, B. Am. Meteorol. Soc., 87, 911-926, 2006.

Chen, D.: A monthly circulation climatology for Sweden and its application to a winter temperature case study, Int. J. Climatol., 20, 1067-1076, 2000.

Cherry, J., Cullen, H., Visbeck, M., Small, A., and Uvo, C.: Impacts of the North Atlantic Oscillation on Scandinavian hydropower Production and energy markets, Water Resour. Manage., 19, 673-691, doi:10.1007/s11269-005-3279-z, 2005.

Christiansen, B.: On the physical nature of the Arctic Oscillation, Geophys. Res. Lett., 29, 1805, doi:10.1029/2002GL015208, 2002.

Dai, A.: Precipitation characteristics in eighteen coupled climate models, J. Climate, 19, 4605-4630, 2006.

Dee, D. P., Uppala, S. M., Simmons, A. J., Berrisford, P., Poli, P., Kobayashi, S., Andrae, U., Balmaseda, M. A., Balsamo, G., Bauer, P., Bechtold, P., Beljaars, A. C. M., van de Berg, L., Bidlot, J., Bormann, N., Delsol, C., Dragani, R., Fuentes, M., Geer, A. J., Haimberger, L., Healy, S. B., Hersbach, H., Hólm, E. V., Isaksen, L., Kållberg, P., Köhler, M., Matricardi, M., McNally, A. P., Monge-Sanz, B. M., Morcrette, J.-J., Park, B.-K., Peubey, C., de Rosnay, P., Tavolato, C., Thépaut, J.-N., and Vitart, F.: The ERA-Interim reanalysis: Configuration and performance of the data assimilation system, Q. J. Roy. Meteor. Soc., 137, 553-597, doi:10.1002/qj.828, 2011.
Fetzer, E. J.: Preface to special section: Validation of Atmospheric Infrared Sounder Observations, J. Geophys. Res., 111, D09S01, doi:10.1029/2005JD007020, 2006.

Førland, E. J., Allerup, P., Dahlström, B., Elomaa, E., Jonsson, J., Madsen, H., Perälä, J., Rissanan, P., Vedin, H., and Vejen, F.: Manual for operational correction of nordic precipitation data, DNMI Report nr. 24/96. Norwegian Meteorological Institute, P.O. Box 43, Blindern, Oslo, Norway, 66 pp., 1996.

Germann, U., Galli, G., Boscacci, M., and Bolliger, M.: Radar precipitation measurement in a mountainous region, Q. J. Roy. Meteorol. Soc., 132, 1669-1692, doi:10.1256/qj.05.190, 2006.

Gustafsson, M., Rayner, D., and Chen, D.: Extreme rainfall events in Southern Sweden: Where does the moisture come from?, Tellus A, 62, 605-616, doi:10.1111/j.1600-0870.2010.00456.x, 2010.

Hellström, C.: Atmospheric conditions during extreme and nonextreme precipitation events in Sweden, Int. J. Climatol., 25, 631-648, 2005.

Hurrell, J. W.: Decadal trends in the North Atlantic Oscillation:Regional temperatures and precipitation, Science, 269, 676679, 1995.

Huuskonen, A., Saltikoff, E., and Holleman, I.: The Operational Weather Radar Network in Europe, B. Am. Meteorol. Soc., online first, doi:10.1175/BAMS-D-12-00216.1, 2013.

Jeong, J.-H., Walther, A., Nikulin, G., Chen, D., and Jones, C.: Diurnal cycle of precipitation amount and frequency in Sweden: observation versus model simulation, Tellus A, doi:10.1111/j.16000870.2011.00517.x, 2011.

Johansson, B. and Chen, D.: The influence of wind and topography on precipitation distribution, A case study in Sweden, Int. J. Climatol., 23, 1523-1535, 2003.

Koistinen, J. and Michelson, D. B.: BALTEX weather radar-based products and their accuracies, Boreal Environ. Res., 7, 153-163, 2002.

Koistinen J. and Puhakka T.: An Improved Spatial Gauge-Radar Adjustment Technique, Preprints 20th AMS Conf. on Radar Met., 30 November-3 December, Boston, MA, 179-186, 1981.

Linderson, M.-J.: Objective classification of atmospheric circulation over Southern Scandinavia, Int. J. Climatol., 21, 155-169, 2001.

Matyas, C. J.: Use of Ground-based Radar for Climate-Scale Studies of Weather and Rainfall, Geography Compass, 4, 1218-1237, doi:10.1111/j.1749-8198.2010.00370.x, 2010.

Michelson, D. B.: Systematic correction of precipitation gauge observations using analyzed meteorological variables, J. Hydrol., 290, 161-177, 2004.

Michelson, D.: The Swedish weather radar production chain, Proc. ERAD 2006, 2006.

Michelson, D. B., Andersson, T., Koistinen, J., Collier, C. G., Riedl, J., Szturc, J., Gjertsen, U., Nielsen, A., and Overgaard, S.: BALTEX Radar Data Centre Products and their Methodologies, SMHI Reports Meteorology and Climatology RMK Nr. 90, SMHI, SE-601 76, Norrköping, Sweden, 76 pp., 2000.

Overeem, A., Holleman, I., and Buishand, A.: Derivation of a 10Year Radar-Based Climatology of Rainfall, J. Appl. Meteorol. Clim., 48, 1448-1463, doi:10.1175/2009JAMC1954.1, 2009.

Rudolph, J. V. and Friedrich, K.: Seasonality of vertical structure in radar-observed precipitation over southern Switzerland, J. Hydrometeorol., 14, 318-330, 2013. 
Rudolph, J., Friedrich, K., and Germann, U.: Relationship between radar-estimated precipitation and synoptic weather patterns in the European Alps, J. Appl. Meteorol. Clim., 50, 944-957, 2011.

Schneider, U., Becker, A., Meyer-Christoffer, A., Ziese, M., and Rudolf, B.: Global Precipitation Analysis Products of the GPCC, Global Precipitation Climatology Centre (GPCC), DWD, Internet Publikation, 1-13, 2011.

Thompson, D. W. J. and Wallace, J. M.: The Arctic Oscillation signature in the wintertime geopotential height and temperature fields, Geophys. Res. Lett., 25, 1297-1300, 1998.

Uvo, C. B.: Analysis and regionalization of northern European winter precipitation based on its relationship with the North Atlantic oscillation, Int. J. Climatol., 23, 1185-1194, doi:10.1002/joc.930, 2003.
Walther, A. and Bennartz, R.: Radar-based precipitation classification in the Baltic area, Tellus A, 58, 331-343, 2006.

Zhang, J., Howard, K., Langston, C., Vasiloff, S., Kaney, B., Arthur, A., Van Cooten, S., Kelleher, K., Kitzmiller, D., Ding, F., Seo, D.-J., Wells, E., and Dempsey, C.: National Mosaic and Multi-Sensor QPE (NMQ) System: Description, Results, and Future Plans, B. Am. Meteorol. Soc., 92, 1321-1338, doi:10.1175/2011BAMS-D-11-00047.1, 2011. 